\title{
Uterine Prolapse Following Fundal Pressure in the First Stage of Labour: A Case Report
}

\author{
J. Tukur, A. O. Omale, H. Abdullahi and Z. Datti \\ Department of Obstetrics and Gynaecology, Aminu Kano Teaching Hospital, Kano, Nigeria \\ Reprint requests to: Dr. Jamilu Tukur, Department of Obstetrics and Gynaecology, Aminu Kano Teaching \\ Hospital, P. M. B. 3452, Kano,Nigeria.E-mail:_tukur@yahoo.com
}

\begin{abstract}
The use of fundal pressure to assist a woman in labor is a controversial procedure. Its benefits are yet to be scientifically confirmed and it is associated with complications such as perineal lacerations, uterine rupture and uterine inversion. A case is reported of a 28year old Gravida 5 Para $4+0$ (3 Alive) who presented to Aminu Kano Teaching Hospital, (AKTH) Kano, Nigeria with uterine prolapse following fundal pressure done in the first stage of labor in a peripheral hospital. She was delivered by Cesarean section and the prolapse successfully reduced under general anesthesia. Health workers need education on the risks associated with fundal pressure. Alternative methods of aiding women in labor should be promoted.
\end{abstract}

\section{Keywords: Fundal pressure, uterine prolapse}

\begin{abstract}
Résumé
L'utilisation de la pression fundale pour assister une femme en travail est une procédure controversiale. Ses bénéfices m'ont pas encore été scientifiquement confirmes et il est associe aux les complications tels que: lacération perinale, rupture de l'utérus et inversion de l'utérus. Il y a eu un reportage d'une femme de 28 ans, G5P4+0 (3 envie) qui s'est présentée au centre universitaire hospitalier de Kano, Nigeria avec une prolapse utérine sur venue après une pression fundale faite pendant la première étape de l'accouchement dans un autre hôpital. L'accouchement s'est fait par caesarienne et la prolapse a été réduite sous anaesthesie générale. Les personnels de santé ont besoin d'être éduquer sur les risques associes a la pression fundale. D'autres méthodes pour aider les femmes en travail doivent être encouragées. Les personnels de santé doivent être éduquer sur les dangers associes a la pression fundale et sa pratique doit être décourager.
\end{abstract}

Mots-clés: Pression fundale, prolapse utérine

\section{Introduction}

Uterine fundal pressure is applied by some health workers including native doctors and traditional birth attendants to women in labor with the belief that it helps to increase expulsive efforts in labor. It is usually applied to women in the second stage of labor who are tired to help expedite the delivery. The use of fundal pressure to assist the second stage of labor is controversial. ${ }^{1}$ A scientific justification for its use is yet to be made. No confirmed benefit from the procedure has been documented. Rather, it has been associated with a number of complications. ${ }^{2}$ Its use to assist the second stage has been found to cause a longer second stage of labor and a higher incidence of third and fourth degree perineal lacerations. ${ }^{3}$ Several reports associate fundal pressure to uterine rupture. . $^{4-6}$ It is also associated with acute puerperal uterine inversion. ${ }^{7}$ These conditions are life threatening to the mother and in the case of ruptured uterus, to the baby too. A case is reported of the consequences of fundal pressure which was done in the first stage of labor.

\section{Case report}

A 28-year-old Gravida 5 Para $4+0$ (3 Alive) presented on the 3rd of September 2006. She was unsure of the date of her last menses but it was sometime nine months earlier. The pregnancy was unbooked. She complained of labor pains of three hours duration and a feeling of a mass in her vagina of one hour duration. She had earlier been to a peripheral Hospital with the complaints of labor pains of three hours. She was admitted for an hour and placed on an intravenous infusion. Fundal pressure was applied to her by the workers on duty which they claimed would help her to deliver the baby. Immediately after, 
she had an urge to bear down. She subsequently noted a fleshy mass protruding from her vagina. She was then referred for further management. She had no history of chronic cough, constipation or abdominal distention. It was her first time of noticing the mass. All her previous pregnancies were uneventful. All the deliveries were at home. Her 3 rd child died at the age of 5 years from malaria. The other children were alive and well. She did not have any chronic medical disorder. She was a full time housewife. She did not smoke cigarettes or drink alcohol.

On examination, she was noted to be a young woman who was in pains, afebrile, not pale and anicteric. The pulse rate was 88 beats per minute and her blood pressure was $120 / 70 \mathrm{~mm} \mathrm{Hg}$. The Heart sounds were I and II only. The chest was clinically clear. The abdomen was enlarged with a symphisiofundal height of $32 \mathrm{~cm}$. The lie was longitudinal with a cephalic presentation. The presenting part was $5 / 5$ palpable per abdomen. She was having three uterine contractions every 10 minutes with each contraction lasting 40-45 seconds. The fetal heart sounds were heard at the rate of 140 beats per minute. Pelvic examination revealed a prolapsed cervix that was oedematous and, stained with thick, slightly blood stained discharge, and the os was $3 \mathrm{~cm}$ dilated (Figure 1). The fetal presenting part as well as the fetal membrane could not be felt through the cervical os as they were both high up in the pelvis. An attempt at replacing the prolapsed cervix to its normal position failed.

Figure 1. Uterovaginal prolapse with oedematous cervix

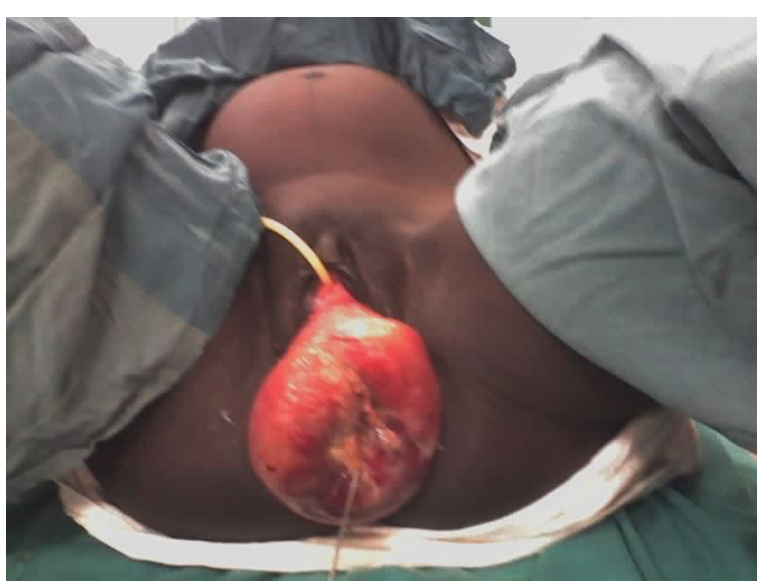

A diagnosis of multipara with a second degree uterine prolapse most likely due to fundal pressure and obstructed labor was made. She was then prepared and delivered by Cesarean section. She was delivered of a live female baby weighing $2.7 \mathrm{~kg}$ with Apgar score 6 and 9 at 1 and 5 minutes respectively. After the Cesarean section, the prolapsed cervix and uterus were successfully reduced back to their normal anatomical position under general anesthesia. A warm vaginal pack was left in the vagina to maintain the cervix in its place for six hours. When it was removed, there was no further prolapse.

Postoperative course was uneventful and she was discharged home after 7 days good condition. Before discharge, she was fully educated on her condition and informed on the need to avail herself of care from reputable health facilities during subsequent delivery. A report on the patient was also sent back to the referring hospital including the need to educate the health workers who did the fundal pressure to desist from doing so. The patient came for post natal visit six weeks after delivery and the prolapse had recurred. She was counselled and has accepted to have a vaginal hysterectomy.

\section{Discussion}

The case presented pinpoints the problems faced by women in the process of delivering their babies in the developing countries. This case presented is pathetic because the woman actually availed herself of supposedly skilled care during delivery, which was expected to provide her with the optimum care she deserved. Rather, she was made a victim of a potentially dangerous procedure of no proved benefit with the resultant consequences. The fact that health workers were trying to deliver her by applying fundal pressure in the first stage of labor showed their basic lack of understanding of the mechanism of normal labor. It cannot in any way be justified, and may cause injury to the baby and mother, including ruptured uterus, $^{4-6}$ apart from precipitating uterovaginal prolapse as occurred in this case. Our literature review could not reveal a previous report of uterine fundal pressure done in the first stage of labor.

Since fundal pressure is associated with several complications, both orthodox and traditional health practitioners should be discouraged from applying it. Fundal pressure is more commonly applied in the second stage of labor. However, when there is delay in the second stage of labor, efforts should be made to find out why and appropriate corrective measures put in place. ${ }^{8}$ Delay in second stage may be caused by inadequate uterine contractions, cephalopelvic disproportion, and maternal exhaustion among other factors. Appropriate measures to address delay may therefore be in the form of augmentation with oxytocics, cesarean section or assisting the labor by forceps or vacuum as the case may be. The case illustrates the need for training and retraining of health care workers to update their knowledge in obstetrics in the form of 'Life Saving Skills (LSS)'.This will enable the correct management of obstetric cases to be given and potentially dangerous procedures such as fundal pressure to be abandoned.

\section{References}

1. Simpson KR, Knox GE. Fundal pressure 
during the second stage of labour. American Journal of Maternal and Child Nursing. 2001;26:21.

2. Merzi ZO, Awonuga AO. The role of uterine fundal pressure in the second stage of labour: A reappraisal. Obstet Gynecol Surv. 2005;60:599603.

3. Cosner KR. Use of fundal pressure during the second stage labour. American Journal of Midwifery. 1996;41:334-337.

4. Vangeenderhuysen C, Souidi A. Uterine rupture of pregnant uterus: Study of a continuous series of 63 cases seen at the referral maternity at Niamey. Med Trop. 2002;62:615-618.
5. Pan HS, Huang LW, Hwang JL, et al. Uterine rupture in an unscarred uterus after application of fundal pressure. A case report. J Reprod Med. 2002;47:1044-1046.

6. Umezurike CC, Feyi-Waboso PA. Ruptured uterus in a primigravida, secondary to abdominal manipulation by a traditional birth attendant: A case report. Trop J Obstet Gynaecol. 2005;22:8384.

7. Lipitz S, Frenkel Y. Puerperal inversion of the uterus. Eur J Obstet Gynecol Reprod Biol. 1988;27:271-274.

8. Orhue AAE. Normal labour. Principles and practice of the conduct of labour. Trop J Obstet Gynaecol. 1998;15:1-14. 